\title{
The effects of bluephase LED light on fibroblasts
}

\author{
Ana Ivanišević Malčić \\ Ivan Pavičić ${ }^{2}$ \\ Ivančica Trošić ${ }^{2}$ \\ Paris Simeon ${ }^{1}$ \\ Davor Katanec ${ }^{3}$ \\ Silvana Jukić Krmek'
}

\section{ABSTRACT}

Objective: The aim of this study was to evaluate the effect of Bluephase light emitting diode (LED) light on cell viability, colony-forming ability and proliferation in V79 cell culture and to determine how much the temperature of the nutrient medium rose.

Methods: The investigation included a low (L), soft start (S) and high (H) illumination mode for 20 , 40 and 80 seconds. The viability was determined by the trypan blue exclusion test, colony-forming ability by counting colonies 7 days after exposure and cell proliferation by the cell counts on 5 postexposure days. The temperature change during illumination was recorded $\left(0.1^{\circ} \mathrm{C}\right.$ sensitivity).

Results: In each experimental condition, $90-95 \%$ of the cells were viable, which was in the same range as the controls. Colony-forming ability was not found to be significantly lower $(P<.05)$. A significant decrease in proliferation was recorded on the 4th post-exposure day with $\mathrm{S}$ and $\mathrm{H}$ irrespective of time, on the $3^{\text {rd }}$ day with $\mathrm{S}$ for $80 \mathrm{~s}$ and $\mathrm{H}$ for 40 and $80 \mathrm{~s}$, and with $\mathrm{S}$ and $\mathrm{H}$ for $80 \mathrm{~s}$ on the $2^{\text {nd }}$ day $(P<.05)$. The temperature rise was significant with $S(P<.05)$ and $H(P<.05)$, irrespective of exposure duration.

Conclusion: Dependent on total energy density, LED blue light affects the mitotic activity of cells in its path to a certain extent. Altered mitotic activity was not noted with illumination at the low power mode (intensity of $421.7 \pm 1.1 \mathrm{~mW} / \mathrm{cm}^{2}$ ). The greatest temperature rise was $8.3^{\circ} \mathrm{C}$ and occurred at the highest intensity and exposure duration. (Eur J Dent 2012;6:311-317)

Key words: Bluephase effects; LED light; fibroblasts

1 Department of Endodontics and Restorative Dentistry, School of Dental Medicine, University of Zagreb, CROATIA

2 Institute for medical research and occupational health, Zagreb, CROATIA

${ }^{3}$ Department of Oral Surgery, School of Dental Medicine, University of Zagreb, CROATIA

- Corresponding author: Dr. Ana I Malčić School of Dental Medicine, University of Zagreb, Gundulićeva 5, 10000 Zagreb, CROATIA

Tel: +38514802126

Fax. +38514802159

Email: amalcicivandagmail.com

\section{INTRODUCTION}

Adequate polymerization of light-cured composite materials is crucial for obtaining satisfactory mechanical properties, and it contributes to the overall clinical performance of direct composite restorations. Light-cured resin composites primarily rely on the sufficient intensity of light to achieve adequate polymerization because the light's intensity and effectiveness decrease as the light becomes absorbed or scattered when passing through the material.'

The desired clinical performance cannot sim- 
ply be achieved by applying higher intensity light to achieve better conversion because high intensity light causes more stress released through faster polymerization. $^{2-4}$ Moreover, the high intensity light can damage the surrounding tissues via the biological effects of blue light and temperature rise, irrespective of the light source used. 5,6,7-8

Due to the heat generated by the curing unit and the exothermic nature of the polymerization process itself, the rise in temperature may cause coagulation of protoplasm, expansion and outflow of fluid from the dentinal tubules, changes in blood vessel structure and tissue necrosis. ${ }^{8,10}$ To prevent tissue-damaging effects due to a rise in temperature and to achieve better marginal adaptation, current light curing devices offer different modes of polymerization. ${ }^{2,11-13}$

Light emitting diodes (LED) are a light source that use low-power GaN (gallium nitride) semiconductors for the generation of blue light and have certain advantages compared to the most widely used quartz-tungsten-halogen (QTH) dental curing units. Filters are not required in LED curing units because the spectrum output is narrow and falls within the absorption spectrum of the camphoroquinone photoinitiator (400-500 nm); therefore, no unnecessary heat is generated, which is not the case with QTH lamps. ${ }^{3}$ Furthermore, the wavelength generated by LED curing units is outside the UV wavelength and is not as dangerous for the eyes as the light produced by QTH curing units, which has a broader spectral distribution . 4,5 LEDs have an expected lifetime of several thousand hours without significant degradation of light intensity over time. ${ }^{11}$

Bluephase LED curing units offer three modes of polymerization (low (L), soft-start (S), and high $(\mathrm{H})$ intensity); the intensities are not much higher than those in standard QTH sources $\left(600 \mathrm{~mW} / \mathrm{cm}^{2}\right)$, but they have shorter exposure times. ${ }^{12,14}$ The applied polymerization mode and the bandwidth of the light output affect the depth of polymerization, degree of conversion and polymerization shrinkage. ${ }^{2}$ The exposure duration of each polymerizing mode (20s, 40s and 80s) also affects the degree of conversion and rise in temperature.

The purpose of this study was to determine whether the blue light generated from the Bluephase LED curing unit can exhibit cytotoxic effects in vitro, alter colony-forming ability or alter cellular proliferation, as well as to determine the rise in temperature at different modes of polymerization and exposure times.

\section{MATERIALS AND METHODS}

Cell culture

A continuous line of V79 cells (lung fibroblasts of the Chinese hamster) was routinely grown in an RPMI 1640 nutrient medium (SIGMA Chemical CO, St. Louis, USA) supplemented with $10 \%$ (vol/vol) heat-inactivated fetal calf serum (SIGMA Chemical CO, St. Louis, USA) and antibiotics $(110 \mathrm{lU} / \mathrm{ml}$ of penicillin and $0.1 \mathrm{mg} / \mathrm{ml}$ of streptomycin). The cells were kept in 25- $\mathrm{cm}^{2}$ flasks (TPP Switzerland) in a humidified atmosphere with $5 \% \mathrm{CO}_{2}$ at $37^{\circ} \mathrm{C}$. Before the experimental procedure, cells were detached using $0.25 \%$ trypsin/EDTA (SIGMA Chemical CO, St. Louis, USA) solution, re-suspended, seeded, and pre-incubated for 24 hours. ${ }^{15}$

\section{Exposure conditions}

The light source used in this study was the Bluephase C8® Light Unit (Vivadent, Schaan, Lichtenstein). The Bluephase C8 $®$ Light Unit (Vivadent, Schaan, Lichtenstein) is a high-performance LED polymerization light. The Bluephase unit has been designed according to EN 61010-1 and complies with the relevant EU regulations /certified by the internationally accredited testing body TüV Product Service and UL/CUL). The device operates at high power (H), low power (L) and soft start (S) modes. The recommended curing times depend on the selected dental material: 10, 20, 30, 40 or 120 seconds. $^{16}$

The operating voltage of the Bluephase curing unit is $100-240 \mathrm{~V}$, and the operating field frequency is $50 / 60 \mathrm{~Hz}$; the wavelength ranges from $430-490$ $\mathrm{nm}$, and the operating temperature ranges from $10-40^{\circ}$ C. $^{16}$

The output intensities for each experimental condition were calculated by dividing the radiant power values by the effective radiation diameter of the light guide. ${ }^{17}$ Radiant power values were obtained using OptometerP9710 (Gigahertz Optik, Germanyl. The calculated intensity values were the following:

- after 20 seconds for $H, S$ and $L$ mode: $753.9 \pm$ $9.4 \mathrm{~mW} / \mathrm{cm}^{2}, 742.2 \pm 2.6 \mathrm{~mW} / \mathrm{cm}^{2}, 421.5 \pm 1.6 \mathrm{~mW} /$ $\mathrm{cm}^{2}$, respectively;

- after 40 seconds for $H, S$ and $L$ mode: 751.6 $\pm 5,3 \mathrm{~mW} / \mathrm{cm}^{2}, 719.5 \pm 33 \mathrm{~mW} / \mathrm{cm}^{2}, 421.7 \pm 1.1 \mathrm{~mW} /$ $\mathrm{cm}^{2}$, respectively;

- after 80 seconds for $H, S$ and $L$ mode: $740.2 \pm$ $8,2 \mathrm{~mW} / \mathrm{cm}^{2}, 735.9 \pm 0.7 \mathrm{~mW} / \mathrm{cm}^{2}, 418.9 \pm 2.6 \mathrm{~mW} /$ $\mathrm{cm}^{2}$, respectively.

Previouly prepared cell samples were exposed to the Bluephase blue light in triplicates as suggested by ISO at H, S and L illumination modes for 
20, 40 and 80 seconds..$^{18}$ The experimental model is shown in Figure 1. Control cells were kept in the same experimental conditions but were not exposed to LED dental curing unit irradiation. The counts for each sample were performed twice by the same person.

Cell viability, colony-forming ability and cell proliferation assay

Cell viability was determined by the Trypan Blue dye exclusion test. ${ }^{15}$ The assay was used to estimate the cytotoxicity of the LED blue light by comparing the number of viable cells in the exposed samples to the matched control samples.

To determine the colony-forming ability, cells were plated in a concentration of 40 cells $/ \mathrm{ml}$. The initial cell suspension volume was $5 \mathrm{ml}$ (200 cells) per Petri dish. Cell samples were exposed to LED blue light as described. Thereafter, the cells were incubated for 7 days without medium change, and then the samples were fixed and stained with $\mathrm{Gi}-$ emsa. The cells were air dried, and the colonies with more than 50 cells were counted. ${ }^{19}$

To determine cell proliferation, V79 cells were

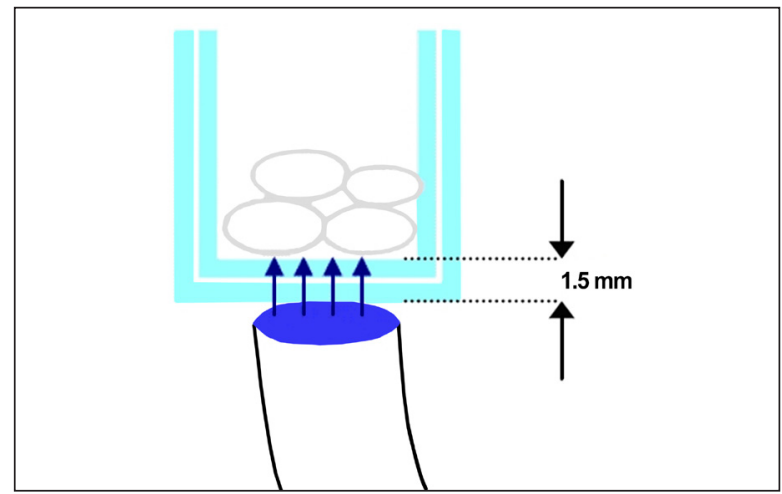

Figure 1. Experimental model

Table 1. Descriptive statistics of V79 colonyforming ability after exposure to low, soft and high illumination mode of Bluephase LED CU for 20, 40 and 80 seconds.

\begin{tabular}{lcccc}
\hline \multicolumn{5}{c}{ Colony forming ability } \\
\hline Mode & Time & Mean & StDev & p \\
\hline \multirow{2}{*}{ Low } & 20 & 44,33 & 5,03 & 0,71 \\
& 40 & 44 & 2,11 & 0,22 \\
& 80 & 41,33 & 3,73 & 0,26 \\
Soft & Control & 45 & 1,76 & 0,12 \\
& 20 & 44,17 & 2,52 & 1 \\
& 40 & 45,33 & 4,84 & 0,09 \\
High & 80 & 42 & 2,88 & 0,1 \\
& Control & 44,17 & 2,27 & 0,38 \\
& 20 & 41,67 & 6,22 & 0,16 \\
\hline
\end{tabular}


mination modes (L, S and H) of Bluephase ${ }^{\circledR}$ Light Source is shown in Table 1. The colony count was not significantly different when compared to controls under all experimental conditions $(P<.05)$.

V79 cell growth after exposure to Bluephase blue light at different modes and exposure times is shown in Table 2. Normal growth of cells occurred in the samples exposed to the L illumination mode, irrespective of exposure duration. In those samples exposed to the $\mathrm{S}$ and $\mathrm{H}$ modes, a significant decrease in proliferation rate was noted on the fourth post-exposure day, irrespective of exposure duration $(P<.05)$. The growth inhibition on the third post-exposure day was noted in the samples that had been illuminated for 40 and 80 seconds with the $\mathrm{H}$ mode and for $80 \mathrm{~s}$ with the $\mathrm{S}$ mode $(P<.05)$. On the second post-exposure day, a significant proliferation decrease was recorded for the $\mathrm{S}$ and $\mathrm{H}$ modes when applied for $80 \mathrm{~s}(\mathrm{P}<.05)$.

\section{Temperature measurements}

Irrespective of exposure duration, the temperature rise in the nutrient medium exposed to the $S$ and $\mathrm{H}$ illumination modes was significant $(\mathrm{P}<.05)$. The rise in temperature in the nutrient medium exposed to the $L$ illumination mode was not significant for any exposure duration. The results of the temperature changes are presented in Table 3. The highest temperature rise was recorded in the exposure to $\mathrm{H}$ illumination mode for 80 seconds: $8.3^{\circ} \mathrm{C}$.

\section{DISCUSSION}

In our investigation, the viability of exposed cell samples was in the same range as the controls for each mode and time combination. A viability as- say was used to measure the proportion of viable cells following a potentially traumatic procedure. Our results suggest that LED blue light does not exhibit highly cytotoxic effects on cells. Similarly, using the same method, it was determined that cell viability is not affected by blue light emitted from a halogen lamp for any polymerization mode and exposure duration. ${ }^{9}$ Nevertheless, it should be taken into consideration that the cell viability test is based on the fact that cells with damaged plasma membranes intake trypan blue dye. Membrane integrity is affected only during the late stages of cell death; therefore, some cells in the earlier stages of apoptosis or necrosis may not be recognized as unviable using this method. Therefore, the combined results of the viability test and other tests should be more informative regarding the possibility of the altered biology of cells upon irradiation.

Colony-forming ability demonstrates the proliferative capacity of several cell generations, and newly formed colonies may be considered representative for the entire cell population. In our investigation, the colony count was lower in comparison to the controls when higher energy density was applied (high mode $x$ the longest exposure), but not significantly. Similarly, the study with the halogen lamp showed that colony-forming abilities were slightly depressed, although not significantly, after exposure, regardless of the exposure duration or illumination mode. ${ }^{9}$

The effect of an agent on cell proliferation can be estimated by counting treated cells after a few days of culture. To avoid any ambiguities that can arise from cell counts at a single point in time, a complete growth curve of cells was done. The pro-

Table 2. Descriptive statistics of V79 cell growth exposed to low, soft and high illumination mode of Bluephase LED CU for 20,40 and 80 seconds.

\begin{tabular}{|c|c|c|c|c|c|c|}
\hline \multicolumn{7}{|c|}{ Cell count (Mean \pm StDev) after Bluephase light $(B)$ exposure } \\
\hline Mode & Time & Day 1 & Day 2 & Day 3 & Day 4 & Day 5 \\
\hline \multirow{4}{*}{ Low } & 20 & $1,46 \pm 0,72$ & $5,71 \pm 1,46$ & $22,17 \pm 3,82$ & $60,13 \pm 4,58$ & $50,04 \pm 7,06$ \\
\hline & 40 & $1,38 \pm 0,58$ & $4,58 \pm 1,02$ & $21,21 \pm 3,71$ & $58,96 \pm 4,15$ & $49,21 \pm 6,30$ \\
\hline & 80 & $1,29 \pm 0,75$ & $4,79 \pm 1,41$ & $22,00 \pm 4,48$ & $58,42 \pm 6,36$ & $47,29 \pm 8,72$ \\
\hline & Control & $1,58 \pm 0,78$ & $5,00 \pm 1,93$ & $23,96 \pm 4,06$ & $60,83 \pm 3,71$ & $49,96 \pm 6,16$ \\
\hline \multirow{4}{*}{ Soft } & 20 & $1,50 \pm 0,93$ & $4,38 \pm 1,21$ & $23,04 \pm 3,18$ & $53,04 \pm 11,3^{*}$ & $46,38 \pm 6,88$ \\
\hline & 40 & $1,42 \pm 0,78$ & $4,38 \pm 1,47$ & $22,54 \pm 3,60$ & $56,96 \pm 4,31 *$ & $49,75 \pm 6,67$ \\
\hline & 80 & $1,33 \pm 1,05$ & $4,04 \pm 1,60 *$ & $20,63 \pm 4,27^{*}$ & $52,67 \pm 4,73^{*}$ & $46,88 \pm 9,65$ \\
\hline & Control & $1,50 \pm 0,72$ & $4,92 \pm 1,38$ & $24,63 \pm 3,79$ & $61,33 \pm 4,93$ & $48,96 \pm 7,07$ \\
\hline \multirow{4}{*}{ High } & 20 & $1,42 \pm 0,83$ & $4,67 \pm 1,46$ & $26,38 \pm 3,16$ & $57,21 \pm 6,73^{*}$ & $43,96 \pm 6,64$ \\
\hline & 40 & $1,29 \pm 0,86$ & $4,58 \pm 1,41$ & $23,54 \pm 4,08^{*}$ & $56,08 \pm 4,72^{*}$ & $43,25 \pm 7,04$ \\
\hline & 80 & $1,21 \pm 1,02$ & $3,71 \pm 1,68^{*}$ & $18,83 \pm 2,75^{*}$ & $53,92 \pm 3,23^{*}$ & $45,33 \pm 9,47$ \\
\hline & Control & $1,42 \pm 0,58$ & $5,21 \pm 1,47$ & $27,71 \pm 2,99$ & $62,13 \pm 5,43$ & $46,58 \pm 7,73$ \\
\hline
\end{tabular}

$(* P<.05)$ 
liferation decrease was proportional to the intensity and exposure duration. A significant decrease in proliferation was observed sooner in the cases where sufficient radiant energy was applied, such as with $\mathrm{H}$ and $\mathrm{S}$ for $80 \mathrm{~s}$, even on post-exposure day 2. The significant differences in cell counts from the controls did not continue on the 5th day; this was possibly a consequence of accomplishing cell culture confluence and depletion of nutrient medium ingredients. In the previous study with a halogen lamp, a significant proliferation decrease was recorded earlier with the exponential and standard modes than with the medium mode. This decrease in proliferation may be explained by the inhibition of mitochondrial succinate dehydrogenase activity and, consequently, the inhibition of the energy-releasing processes. ${ }^{7}$ Furthermore, mitochondria contain many cytochromes and flavins (coenzymes of succinic dehydrogenase) that absorb blue light. ${ }^{6}$ Cell division consumes considerable amounts of energy; therefore, it is logical that a decrease in proliferation is observed in the case where less energy is released due to the inhibitory blue light effect. Furthermore, it has been reported that blue light exhibits its biological effects by generating intracellular reactive oxygen species. ${ }^{5}$ Also, the production of reactive oxygen species has recently been reported as an early expression of cellular stress in the cytotoxicity of dental resin monomers. ${ }^{21}$ Reactive oxygen species cause peroxidation and oxidation of proteins, lipids and nucleic acids and might ultimately induce cell death. ${ }^{21}$ In future research, it would be interesting to estimate the generation of reactive oxygen species in cells simultaneously exposed to dental restorative materials and polymerizing light and to possibly relate the degree of conversion, the intensity of blue light and the intracellular reactive oxygen species production.
Knežević et $a^{22}$ tested the cyto- and genotoxic effects of blue light at different polymerization modes of Bluephase C8 on lymphocyte cultures and found that longer exposure to low intensity light caused more damage to DNA and significantly increased the number of nonviable lymphocytes. This means that exposure duration is crucial in triggering non-favorable cellular events leading to apoptosis and necrosis. However, our results show that cell viability and dividing potential were least affected when the low mode was applied. Nevertheless, it is difficult to compare the results of different in vitro (cell culture) experiments because of different experimental conditions and different parameters being recorded. Therefore, changes on the level of the genome should not necessarily affect mitosis and the rate of proliferation. On the contrary, the rate of proliferation may even be increased due to genotoxic changes affecting the genes regulating cell growth and division.

In addition to interfering with normal cellular energy-releasing pathways, the curing light may exhibit its cytotoxic effect via a rise in temperature. Irrespective of the exposure duration, a rise in temperature in the nutrient medium exposed to the $\mathrm{S}$ and $\mathrm{H}$ illumination modes was significant, while the temperature rise in the nutrient medium exposed to the L illumination mode was not significant for any exposure duration. These results agree with the previous finding that the rise in temperature is proportional to the intensity of light. ${ }^{8}$ The temperature rise with high energy output LED curing units has been reported to be smaller than with halogen lamps because the irradiation spectrum of QTH devices includes wavelengths that induce heating. $2,8,23$ However, Atai and Motevasse$\operatorname{lian}^{24}$ reported that LEDs exhibit higher temperature increases than QTH lamps without improvements in the degree of conversion. Moreover, it

Table 3. Descriptive statistics of data on temperature changes in the nutrient medium exposed 20, 40 and 80 seconds to the Low, Soft and High illumination mode.

\begin{tabular}{lccc}
\hline \multirow{2}{*}{ Mode } & Time & Initial Temperature & Temperature after illumination \\
& Sec. & mean \pm StDev ${ }^{\circ} \mathrm{C}$ & $27,1 \pm 0,2$ \\
Low & 20 & $26,5 \pm 0,4$ & $26,7 \pm 0,4$ \\
& 40 & $26,5 \pm 0,7$ & $27,1 \pm 0,5$ \\
& 80 & $26,3 \pm 0,3$ & $30,8 \pm 0,4^{*}$ \\
Soft & 20 & $26,6 \pm 0,06$ & $32,3 \pm 1,2 *$ \\
& 40 & $26,1 \pm 0,2$ & $34,4 \pm 0,8^{*}$ \\
High & 80 & $26,1 \pm 0,06$ & $30,4 \pm 0,4^{*}$ \\
& 20 & $26,8 \pm 0,1$ & $33,1 \pm 0,8^{*}$ \\
\hline
\end{tabular}

$\left({ }^{*} \mathrm{P}<05\right)$. 
has also been reported that a slightly greater degree of conversion is achieved with QTC lamps. ${ }^{2}$ It is possible that the chemical kinetics and thermodynamics in photopolymerization induced by LED light are such that the process is more exothermic, but this would only partly explain these results because the most significant source of heat during polymerization is the curing unit irradiation and not the setting material. ${ }^{25}$

There is no simple algorithm to determine the overall toxicity of the curing light and composite material. A number of studies have shown that the type of curing unit and mode of polymerization affect the material's cytotoxicity. ${ }^{25-29}$ This is probably because different modes of curing create different polymer network structures with different mechanical properties and cytotoxicity. Furthermore, Wataha et $\mathrm{al}^{6}$ found that the biological effects of light are dependent on the outputs of commonly used light curing devices and not only on the total energy irradiated. Absorbed radiation may cause toxic reactions in the patient's mucosa, and due to back-reflection, in the operator's eyes and skin. ${ }^{5}$

The use of blue light sources at clinically relevant exposure energies poses at least some risk to gingival and pulpal cells in the light's path. Except in the case of direct pulp capping with adhesive, pulpal tissue is rarely directly exposed to blue light; however, photopolymerization of cervical lesions may alter gingival cell function, especially in patients taking photosensitizing drugs or those who have a photosensitizing disease, such as porphyria. Due to back-reflection, blue light may promote unfavorable cellular events in the operator's retina because the intensity of light emitted from the dental curing units is relatively high, and on excessive exposure, the physiologic repair mechanisms may be decompensated, leading to degenerative macular degeneration. ${ }^{5}$ Furthermore, it was reported that high-power LED units of the latest generation, including Bluephase, have a curing time that can be reduced to 20 seconds to obtain durable results for $2-\mathrm{mm}$ thick increments of resin composite. ${ }^{30}$ In the context of our findings, where intensities from $421-754 \mathrm{~mW} / \mathrm{cm}^{2}$ applied for $20 \mathrm{~s}$ exhibited minimal effects on cells at a $1.5-\mathrm{mm}$ distance, it can be concluded that the exposure time of 20 s for a 2-mm thick composite increment results in an adequate degree of conversion and has a minimal blue light biological effect on irradiated cells.

\section{CONCLUSIONS}

The current study demonstrates the following:

- blue light generated by the Bluephase LED dental curing unit does not exhibit highly cytotoxic effects in vitro;

- depending on the total energy density, LED blue light can somewhat affect cellular division;

- illumination at low power mode lintensity of $421.7 \pm 1.1 \mathrm{~mW} / \mathrm{cm}^{2}$ ) does not affect the mitotic activity of cells in the blue light's path;

- a rise in temperature at the highest intensity and exposure duration was $8.3^{\circ} \mathrm{C}$

\section{Acknowledgements}

The research reported here was supported by the Ministry of Science, Education and Sports, Republic of Croatia, Grants No. 665-0650445-0434 and 022-0222411-2406.

\section{REFERENCES}

1. Vargas MA, Cobb DS, Schmit JL. Polymerization of composite resins: argon laser vs. conventional light. Oper Dent 1998;23:87-93

2. Tarle Z, Knežević A, Demoli N, Meniga A, Šutalo J, Unterbrink G, Ristić M, Pichler G. Comparison of Composite curing parameters: effects of light source and curing mode on conversion, temperature rise and polimerization shrinkage. Oper Dent 2006;31-2:219-226.

3. Jandt KD, Mills RW, Blackwell GB and Ashworth S. Depth of cure and compressive strength of dental composites cured with blue light emitting diodes (LEDs). Dent Mater 2000;16:41-47

4. Krämer N, Lohbauer U, García-Godoy F, Frankenberger R. Light curing of resin-based composites in the LED era. $\mathrm{Am}$ J Dent 2008;21:135-142.

5. Bruzell Roll EM, Jacobsen N, Hensten-Pettersen A. Health hazards associated with curing light in the dental clinic. Clin Oral Invest 2004;8:113-117.

6. Wataha JC, Lewis JB, Lockwood PE, Hsu S, Messer RL, Rueggeberg FA, Bouillaguet S. Blue Light Differentially Modulates Cell Survival and Growth. J Dent Res 2004;83:104-108.

7. Wataha JC, Lockwood PE, Lewis JB, Rueggeberg FA, Messer RLW. Biological effects of blue light from dental curing units. Dent Mater 2004;20:150-157.

8. Knežević A, Tarle Z, Meniga A, Šutalo J, Pichler G. Influence of light intensity from different curing units upon composite temperature rise. J Oral Rehabil 2005;32:362-367. 
9. Krmek SJ, Trošić I, Pavičić I, Keros J, Simeon P, Malčić A Mehičić GP. Dose- and Mode- dependent effect of halogen dental curing blue light on the V79-cell line. Coll Antropol 2008:32:913-918

10. Kaup M, Ramb HJ, Dammaschke T, Ott K. Temperaturentwicklung im Pulpakavum bei Herstellung von provisorischen Versorgungen. Deutsche Zahnärztliche Zeitschrift 2000;55:180-182.

11. Stahl F, Ashworth SH, Jandt KD, Mills RW. Light emitting diode (LED) polymerization of dental composites: flexural properties and polymerization potential. Biomaterials 2000;21:1379-1385.

12. Yoon TH, Lee YK, Lim BS, Kim C-W. Degree of polymerization of resin composites by different light sources. $J$ Oral Rehabil 2002;29:1165-1173.

13. Yap AU, Soh MS. Curing efficacy of a new generation high power LED lamp. Oper Dent 2005;30:758-763.

14. Caughman WF, Rueggeberg FA, Curtis JW. Clinical guidelines for photocuring restorative resins. J Am Dent Assoc 1995;126:1280-1286

15. Freshney RI. Cytotoxicity, Protocol 21.1. In Freshney RI, editor. Culture of animal cells. A manual of basic technique. $4^{\text {th }}$ ed. New York: Wiley-Liss Publication; 2000. p. 330-332.

16. Bluephase - Operating instructions, IvoclarVivadent, Schaan, Liechtenstein

17. Ulbricht Sphere - Operating instructions, Gigahertz Optik, Puchheim, Germany

18. International Organization for Standardization. Biological evaluation of medical devices. Part 5. Tests for cytotoxicity: in vitro methods. In: ISO 10993/EN 30993. $1^{\text {st }}$ ed. Genève; 1992.

19. Paul J. Cell Lines: Cloning Cells. In Paul J, editor. Cell and Tissue Culture. $4^{\text {th }}$ ed. Edinburgh: E. S. Livingstone LTD 1970. p. 234-242.

20. Freshney RI. Quantitation. In Freshney RI, editor. Culture of animal cells. A manual of basic technique. $4^{\text {th }}$ ed. New York: Wiley-Liss Publication; 2000. p. 319-323.

21. Spagnuolo G, Annunziata M, Rengo S. Cytotoxicity and oxidative stress caused by dental adhesive systems cured with halogen and LED lights. Clin Oral Investig 2004;8:81-85

22. Knežević A, Željezic D, Kopjar N, Tarle Z. Influence of curing mode intensities on cell culture cytotoxicity/genotoxicity. Am J Dent 2009;22:43-48.

23. Dogan A, Hubbezoglu I, Dogan OM, Bolayir G, Demir H. Temperature rise induced by various light curing units through human dentin. Dent Mater J 2009;28:253-260.

24. Atai M, Motevasselian F. Temperature rise and degree of photopolymerization conversion of nanocomposites and conventional dental composites. Clin Oral Investig 2009:3:309-316
25. Sigusch BW, Völpel A, Braun I, Uhl A, Jandt KD. Influence of different light curing units on the cytotoxicity of various dental composites. Dent Mater 2007;23:1342-1348.

26. Knezevic A, Zeljezic D, Kopjar N, Tarle Z. Cytotoxicity of composite materials polymerized with LED curing units. Oper Dent 2008;33-1:23-30.

27. Beriat NC, Ertan AA, Canay S, Gurpinar A, Onur MA. Effect of different polymerization methods on the cytotoxicity of dental composites. Eur J Dent 2010;4:287-292.

28. Sigusch BW, Pflaum T, Völpel A, Schinkel M, Jandt KD. The influence of various light curing units on the cytotoxicity of dental adhesives. Dent Mater 2009;25:1446-1452.

29. Yap AU, Saw TY, Cao T, Ng MM. Composite cure and pulpcell cytotoxicity associated with LED curing lights. Oper Dent 2004;29:92-99.

30. Schattenberg A, Lichtenberg D, Stender E, Willershausen $B$, Ernst CP. Minimal exposure time of different LED-curing devices. Dent Mater 2008;24:1043-1049. 